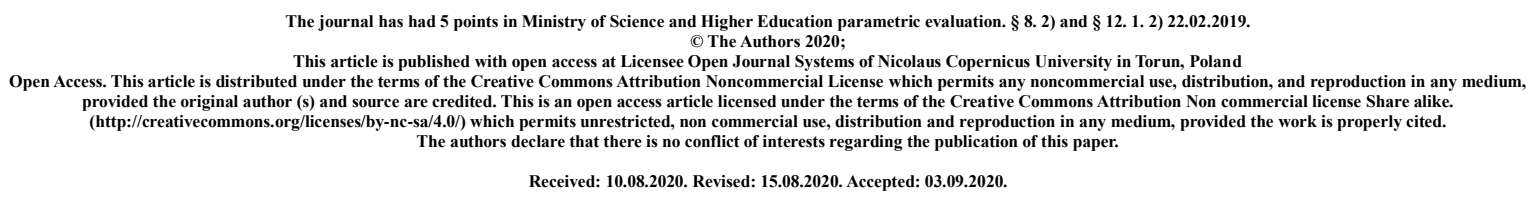

\title{
Is polio eradication possible?
}

\author{
Kinga Ruszel ${ }^{1}$, Barbara Nieradko-Iwanicka² \\ ${ }^{1}$ Students' Scientific Association at the Chair and Department of Hygiene, Medical University \\ of Lublin \\ ${ }^{2}$ Chair and Department of Hygiene, Medical University of Lublin \\ Corresponding author: Barbara Nieradko-Iwanicka
}

\begin{abstract}
Poliomyelitis is called childhood paralysis, anterior horn inflammation of the spinal cord and Heine-Medin disease. Poliomyelitis is caused by poliovirus. Infection spreads through ingestion of objects and foodstuffs contaminated with pharyngeal secretions or faeces. The virus multiplies in the intestine, from where it can attack the nervous system and can cause paralysis that is often permanent. The initial symptoms of polio include fever, headache, vomiting, stiff neck, and pain in the extremities. Majority of cases is either completely asymptomatic or result in a mild disease typical of a generalized viral infection; Poliomyelitis paralysis occurs in $0.1-1 \%$ of infections. There is no cure for polio, it can only be prevented by immunization. In 1988, the World Health Assembly adopted a resolution that committed all countries to polio eradication by the year 2000 .

The aim of the review is to summarize data on the incidence of polio virus infection in recent years in the world.

PubMed databases and statistics from the Centers for Disease Control and Prevention (CDC), Polio Global Eradication Initiative and world data from WHO websites were searched in July and August 2020. In PubMed we used any text and medical terms 'polio', 'poliomyelitis', 'polio vaccine'. Twenty two publications were cited.

In conclusion: Majority of the wold is free from polio. Polio still spreads in several countries.
\end{abstract}


In a country which is not free of polio all residents and long-term visitors ( $>$ four weeks) of all ages, should receive a dose of bivalent oral poliovirus vaccine (bOPV) or inactivated poliovirus vaccine (IPV) between four weeks and 12 months prior to international travel. It can helps with restrict of transmission of polio outside the border.

Key words: poliovirus, poliomyelitis, vaccine, epidemiology, eradication

\section{Introduction}

Polio is a disease known since ancient times At the beginning of the 20th century, immunity of infants decreases and poliomyelitis spread (1).

Poliomyelitis was called childhood paralysis, anterior horn inflammation of the spinal cord and Heine-Medin disease. Poliomyelitis is caused by poliovirus, a picornavirus with a small, lipid-free virion that causes disease mainly in children. It is highly contagious and dangerous, because the immune system of children cannot always cope with it, due to insufficient maturity of the cells of the system. There are three types of polioviruses - 1,2 and 3. Getting sick from one type does not protect against the other types. Infection spreads through ingestion of objects and foodstuffs contaminated with pharyngeal secretions or faeces. The virus multiplies in the intestine, from where it can attack the nervous system and can cause paralysis that is often permanent. The incubation period of the disease ranges from 3 to 35 days, including 3 to 6 days for the uninfected form and 7 to 21 days for the paralytic form. Patients shed viruses in their faeces for up to 6 weeks. The period of greatest infectivity occurs from a few days before the first symptoms of the disease appear to 3-4 weeks after their onset (2). Initial symptoms of polio include fever, fatigue, headache, vomiting, stiff neck, and pain in the extremities (Fig. 1.). Infections with the polio virus most often proceed without paralysis: they are asymptomatic in $90-95 \%$ of cases or abortive in the form of fever, headaches, gastrointestinal symptoms in $4-8 \%$. Some infections run as serous aseptic meningitis. Polio affects the quality of life of those who have suffered from it and causes health problems including the post-polio syndrome $(3,4)$. Interestingly, it has been observed in new research that colon cells infection with polio virus can induce a certain degree of resistance to the development of colon cancer decades later. The effect of poliovirus infection appears to be particularly strong in reducing colon cancer mortality (5) .

The prevention and control of poliomyelitis consists of the action aiming to inactivate the source of the infection, cut the pathways of spreading the infection and increase the resistance of people susceptible to infection. Therefore, the vaccine is the most important target for viral eradication. Vaccines were invented in the 1950s and introduced into mass use in most countries as early as the second half of the 1950s (3). 


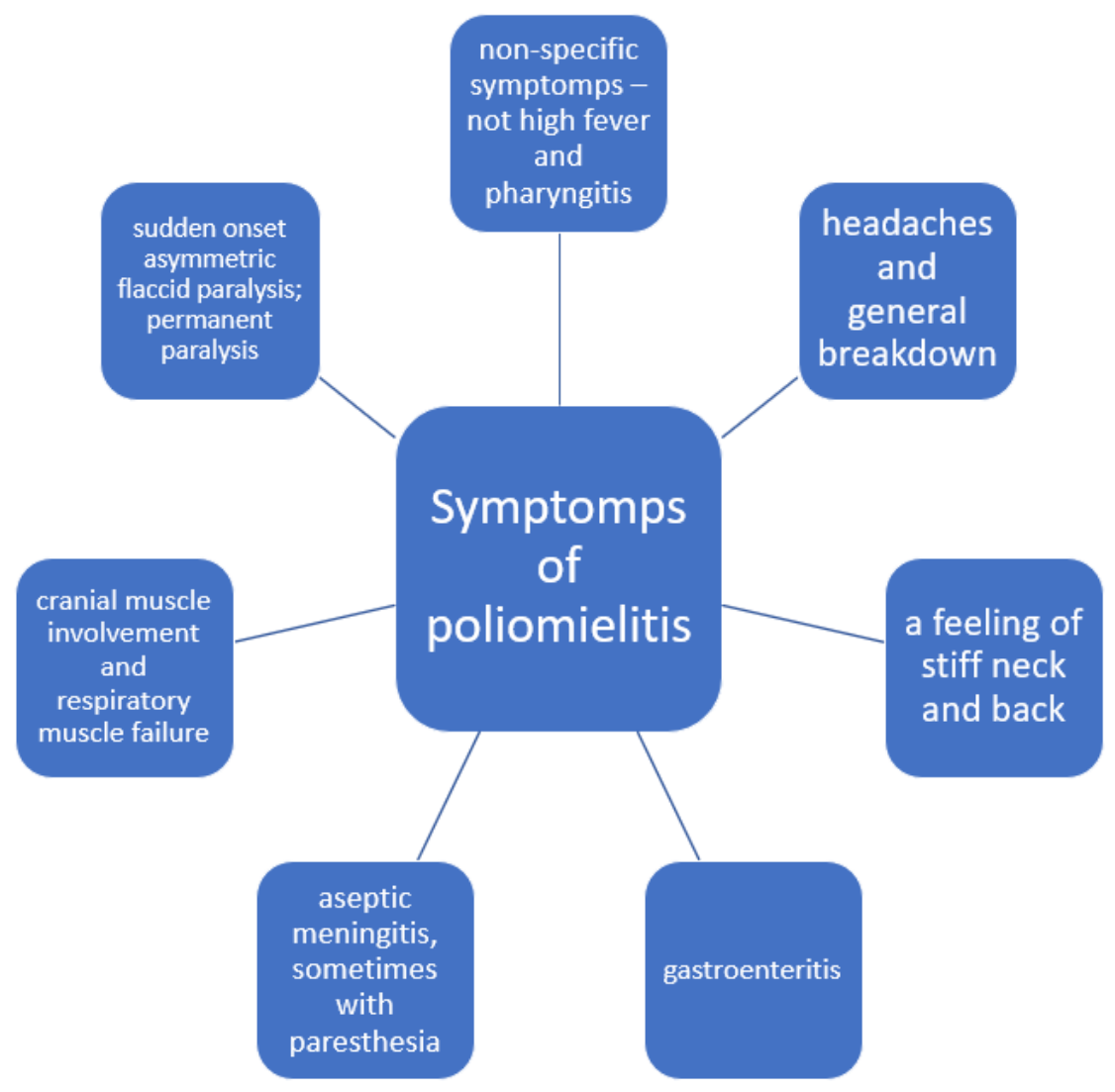

Figure 1. Symptoms of poliomyelitis

\section{Aim}

The aim of the review is to summarize data on the incidence of polio virus infection in recent years in the world. Since 1988, several WHO Regions have been certified polio-free, including the Americas (in 1994), the Western Pacific Region (in 2000), the European Region (in 2002), and the South-East Asia Region, which includes the Indian subcontinent and Indonesia (in 2014). Still we are waiting for improvement of morbidity for the rest countries, which are fighting with polio.

\section{Materials and methods}

PubMed databases and statistics from the Centers for Disease Control and Prevention (CDC), Polio Global Eradication Initiative and world data from WHO websites were searched in July and August 2020. In PubMed we used any text and medical terms 'polio', 'poliomyelitis', 'polio vaccine'. No language restrictions were added. Twenty two publications were cited.

\section{Results}

Currently, there are two endemic countries where polio virus infections have been observed. They are: Afghanistan and Pakistan. Nigeria returned to the list of endemic countries following the detection of wild type 1 polio virus (WPV1) in August 2016, and was removed from the list in 2020 . 
In the same year, a fairly low number of polio cases was recorded - only 37 , which is exactly half of the 74 cases reported in 2015. In 2017, there were even fewer cases: only 22 by the end of October (the year before, 27 cases were reported in the same period). However, in the following years, in 2018 (33 cases WPV1, 104 cases cVDPV) and 2019 (176 cases WPV1, 368 cases cVDPV) there was a renewed increase in the number of polio infected cases with a further increase in 2020 (81 cases WPV1, 194 cases cVDPV on July 2020 (6).

The risk of international spread of poliovirus remains a Public Health Emergency of International Concern (PHEIC) and its spread is at the highest point since 2014. This risk assessment is based on the ongoing WPV1 exportation from Pakistan to Afghanistan, and from Afghanistan to Pakistan; ongoing rise in the number of WPV1 cases and positive environmental samples in both Pakistan and Afghanistan with formerly polio free areas within the countries reporting cases in 2020 and the quickly increasing cohort of inaccessible unvaccinated children in Afghanistan. The COVID-19 pandemic has had a significant impact on public health programs, including polio eradication. Border closures and blockades can reduce risks in the short term. However this will be offset in the longer term by a decline in population immunity as vaccination is discontinued and normal movements resume. It is important to maintain high childhood immunization rates, encourage travellers to high-risk countries to check their polio vaccination status, and ensure strong surveillance of the entire healthcare system for polio-like diseases. The knock-on effect of failing to meet the polio goal would have a profound detrimental effect on other global health initiatives, including the elimination of measles and rubella. One great final effort is needed to rid the world of this contagious plague once and for all. The strategic plan to end polio required the sequential removal of Sabina polio virus serotypes from the trivalent oral polio vaccine (tOPV) and the introduction of $\geq 1$ dose of inactivated polio vaccine (IPV) to maintain the basis of immunity against polio type 2 viruses. Two doses of fIPV were found to be more immunogenic than a single full dose, which is associated with significantly increased seroconversion rates and antibody titres. Therefore, a two-dose schedule of FIPV (Fractional IPV, in which one-fifth $(0.1 \mathrm{ml})$ of the full dose of intramuscular IPV $(0.5 \mathrm{ml}))$ at 6 and 14 weeks of age has been approved in some affected countries (7) The basis of the virus type 2 immunity should reduce the paralytic consequences of exposure to type 2 polio virus and improve the immune response. The introduction of IPV (in countries that previously only used OPV) increased global demand for IPV, both standalone and used in combination vaccines, from around 80 million doses in 2013 to around 200 million doses in 2016 (8).

The Global Commission for the Certification of the Eradication of Poliomyelitis certified the eradication of WPV2 in September 2015, making WPV2 the first human pathogen to be eradicated after smallpox (9). Nevertheless, other strains of the virus still remain unchallenged and infect people in few countries.

Only 2 countries (Pakistan and Afghanistan) and recently Nigeria have never interrupted indigenous poliovirus transmission. The persistent safe haven for the polio virus in the northern states of Nigeria and in the border areas between Pakistan and Afghanistan have repeatedly spread the virus to other countries, both to neighboring countries and beyond (10). 
The eighteenth meeting of the Emergency Committee under the International Health Regulations (IHR) regarding the international spread of poliovirus was convened by the Director General on 15 August 2018. The following countries provided updated information on the situation and implementation of WHO's interim recommendations: Afghanistan, the Democratic Republic of the Congo (DR Congo), Nigeria, Pakistan, Papua New Guinea (PNG) and Somalia. The number of cases worldwide remained low in 2018 (total cases - 33), however The Committee was very concerned by the increase in WPV1 cases in Afghanistan in 2018. The number of WPV1 cases remained low and from October 2017 (until April 2018) WPV1 did not spread internationally (11). These numbers were still low in comparison to 2015 and 2016 (Tab. 1.).

Tab.1. Poliomyelitis cases in 2015 and 2016.

\begin{tabular}{|lcc|lcc|}
\hline $\mathbf{2 0 1 5}$ & WPV1 & cVDPV & 2016 & WPV1 & cVDPV \\
\hline Globally & 74 & 32 & Globally & 37 & 5 \\
\hline Nigeria & - & 1 & Nigeria & 4 & 1 \\
\hline Afganistan & 20 & - & Afganistan & 13 & 0 \\
\hline Pakistan & 54 & 2 & Pakistan & 20 & 1 \\
\hline
\end{tabular}

The nineteenth meeting of the Emergency Committee was on 27 November 2018 . There was an increase in the number of WPV1 cases worldwide in the second half of the year (especially in Afghanistan, the number almost doubled: from 19 cases reported by November, compared to 10 at the same time the year before), and there was a cross-border spread of wild polio virus. In Pakistan, the number of cases in 2018 was at the same level as in 2017 as a whole. Somalia and Kenya, and the spread of cVDPV2 from Nigeria to Niger, showed that traditionally cVDPV viruses rarely spread across borders. The coverage of routine vaccinations was still very low then (12).

The twentieth meeting of the Emergency Committee under the International Health Regulations (IHR) regarding the international spread of poliovirus was on 19 February 2019. However, the Committee was very concerned about the increase in the number of WPV1 cases worldwide in 2018 (33 cases total WPV1 and 104 cVDPV) with more cases in Nigeria and Pakistan than in 2017 (Tab.2.) (13).

Tab.2. Poliomyelitis cases in 2017 and 2018.

\begin{tabular}{|lcc|lcc|}
\hline $\mathbf{2 0 1 7}$ & WPV1 & cVDPV & $\mathbf{2 0 1 8}$ & WPV1 & cVDPV \\
\hline Globally & 22 & 96 & Globally & 33 & 104 \\
\hline Nigeria & - & - & Nigeria & 15 & 34 \\
\hline Afganistan & 14 & - & Afganistan & 13 & 21 \\
\hline Pakistan & 8 & - & Pakistan & 58 & 12 \\
\hline
\end{tabular}

The twenty-first meeting was on 14 May 2019. The following countries provided an update on the situation and implementation of WHO's interim recommendations since the last committee meeting on 19 February 2019: Afghanistan, DR Congo, Indonesia, Nigeria, Pakistan and Somalia. 
It was noted that an increasing number of cases in Pakistan and Afghanistan occurred during that part of the year which was usually considered to be of low transmission. Additionally, increasing social and individual resistance to the polio control program has been observed. The growing risk of spreading cVDPV: the newly developed cVDPV2 strain in Nigeria and the Democratic Republic of the Congo was also worrying. There were also problems with poor routine vaccination systems and gaps in access to vaccines, affected by various crises, conflicts and complex emergencies (14).

On 16 September 2019 was the twenty-second meeting and the twenty-third meeting was held on 11 December 2019 of the Emergency Committee under the International Health Regulations (IHR) regarding the international spread of poliovirus. The Emergency Committee reviewed data on wild-type poliovirus (WPV1) and circulating vaccine-derived polio viruses (cVDPV). There was a further significant increase in the number of WPV1 cases worldwide to 176 in 2019. The increase is due to the ongoing epidemic in Pakistan. In Pakistan, the growing refusal by individuals and communities to accept immunization has been a serious obstacle to fight the infection (15). In Afghanistan, the deteriorating security environment has severely hampered progress towards global polio eradication. Inaccessible and lost children (especially in the south) have caused and continue to make Afghanistan a large and growing group of children susceptible to the disease. The risk of the virus spreading internationally was again increasing. In Nigeria no WPV1 virus has been detected in three years and it is possible that the African region could be certified WPV free in 2020. The rapidly growing number of unvaccinated children in Afghanistan threatened to outbreak, which also exacerbated declining immunity to PV2 in children, gaps in surveillance, temporary lack of vaccine supply, population movements and the evolution of cVDPV2 strains $(15,16)$.

The Twenty-fourth meeting of the Emergency Committee under the International Health Regulations (IHR) on the international spread of poliovirus was on 26 March 2020. The Committee remains gravely concerned by the significant increase in WPV1 cases globally in 2019 and 2020, with 176 cases in 2019 compared to 33 in 2018. In Pakistan, spread of the disease was still widespread. Issues of refusing vaccinations by individuals and communities, as well as problems with managing the national polio program, have become a growing concern. There is an increasing number of outbreaks of VDPV (VDPV - Vaccine derived poliovirus (VDPV)) in four regions (Eastern Mediterranean, Southeast Asia and Western Pacific). Two new countries have reported outbreaks since the last meeting (Malaysia and Burkina Faso). The coronavirus infection disease (COVID-19) pandemic can adversely affect polio eradication efforts and may increase viral transmission. There is a risk of exportation of both WPV1 and cVDPV to known high risk countries, to which it may take a lot of time and effort to adequately respond. Many countries have weak immunization systems that can be further impacted by various humanitarian emergencies including COVID19 (17).

The last one, the twenty-fifth meeting of the Emergency Committee on the international spread of poliovirus was on 23 June 2020. As it turns out, the number of outbreaks of vaccinederived polio virus type 2 (cVDPV2) is significantly greater than expected. The novel oral polio vaccine type-2, which will be made available under the Emergency Use Listing procedure (EUL), is expected to be an important new tool to stop the vicious cycle of using monovalent Sabin OPV2 to combat outbreaks, but in turn seeding new outbreaks of cVDPV2. 
Still the global situation remains of great concern with the increased number of WPV1 cases that started in 2019 continuing in 2020. This year there have been 70 WPV1 cases as at 16 June 2020, compared to 57 for the same period in (18) (Tab.3.).

Tab.3. Poliomyelitis cases in 2019 and 2020.

\begin{tabular}{|lcc|lcc|}
\hline $\mathbf{2 0 1 9}$ & WPV1 & cVDPV & until July 2020 & WPV1 & cVDPV \\
\hline Globally & 176 & 368 & Globally & 81 & 194 \\
\hline Nigeria & - & 18 & Nigeria & - & 1 \\
\hline Afganistan & 29 & - & Afganistan & 26 & 17 \\
\hline Pakistan & 147 & 22 & Pakistan & 55 & 47 \\
\hline
\end{tabular}

Other states infected with WPV1, cVDPV1 or cVDPV3 with potential risk of international spread were enumerated in Table 4. (18):

Tab.4. States infected with WPV1, cVDPV1 or cVDPV3 with potential risk of international spread.

\begin{tabular}{|l|l|}
\hline WPV1: & \\
\hline $\begin{array}{l}\text { Afganistan } \\
\text { Pakistan }\end{array}$ & $\begin{array}{l}\text { (most recent detection 27 May 2020) } \\
\text { (most recent detection 8 June 2020) }\end{array}$ \\
\hline cVDPV1 & \\
\hline Malaysia & $\begin{array}{l}\text { (most recent detection 12 February 2020) } \\
\text { Myanmar } \\
\text { Philippines }\end{array}$ \\
\hline
\end{tabular}

States infected with cVDPV2s, with potential or demonstrated risk of international spread were enumerated in Table.5.(18). 
Tab.5. States infected with cVDPV2s, with potential or demonstrated risk of international spread.

\begin{tabular}{|l|l|}
\hline cVDPV2s & \\
\hline Afghanistan & (most recent detection 15 May 2020) \\
Angola & (most recent detection 9 February 2020) \\
Benin & (most recent detection 16 January 2020) \\
Burkina Faso & (most recent detection 30 March 2020) \\
Cameroon & (most recent detection 5 May 2020) \\
Central African Republic & (most recent detection 5 February 2020) \\
Chad & (most recent detection 9 May 2020) \\
China & (most recent detection 18 August 2019) \\
Cote d'Ivoire & (most recent detection 9 May 2020) \\
Democratic Republic of the Congo & (most recent detection 8 February 2020) \\
Ethiopia & (most recent detection 16 March 2020) \\
Ghana & (most recent detection 11 March 2020) \\
Malaysia & (most recent detection 22 January 2020) \\
Mali & (most recent detection 6 February 2020) \\
Niger & (most recent detection15 March 2020) \\
Nigeria & (most recent detection 1 January 2020) \\
Pakistan & (most recent detection 2 May 2020) \\
Philippines & (most recent detection 16 January 2020) \\
Somalia & (most recent detection 8 May 2020) \\
Togo & (most recent detection 3 May 2020) \\
Zambia & (most recent detection 25 November 2019) \\
\hline
\end{tabular}

There are three possible solutions:

1. 12 months from the date of the last case, other people, especially those with similar symptoms, should be examined and meticulous laboratory tests for polio should be performed.

2. Community environmental isolation in the country 12 months after the last Positive Development Assessment has been taken plus laboratory testing and reporting period.

3. When a country meets the criteria as not already infected, considered susceptible to infection for 12 months examination. After this period, the country will no longer be subject to interim recommendations unless the Committee takes a position based on the final report (14).

Vaccines and the ability to prevent morbidity and mortality due to infectious diseases have been one of the greatest public health success stories. On a global level, it is one of the few cost-effective medical measures that result in universal benefit. Despite this, there is evidence of a growing anti-vaccine movement (19). Vaccine hesitancy is a reluctance to be vaccinated or to have one's children vaccinated against despite the availability of vaccination services. It is identified by the WHO as one of the top ten global health threats. 
The phenomenon has taken hold in a number of countries around the world in recent times, and notably in the U.S. as well. In 2017, the percentage for American children aged 19-35 months who did not receive any immunizations quadrupled since 2001 (20). A social movement of public health vaccine opposition has been growing in the United States in recent years; subsequently, measles outbreaks have also increased. New foci of antivaccine activities are being established in metropolitan areas, rendering select cities vulnerable for vaccinationpreventable diseases (21). According to the WHO, immunization prevents between 2 million to 3 million deaths every year across the world. Despite that claims, due to parental concerns about vaccine safety and efficacy, many families choose to opt out their children from vaccinations required for school entry by obtaining nonmedical exemptions (NMEs) based on religious or philosophical beliefs. Regarding concerns about vaccines and autism, the peerreviewed literature does not recognize a link between vaccines and autism spectrum disorder. But when immunization rates are low, disease outbreaks may occur, creating a health and economic toll. Recently, communities in Minnesota and Washington experienced outbreaks of measles and mumps, respectively, due to low vaccination rates among certain populations (22). It happens not only in U.S. but also in countries which are fighting polio.

\section{Conclusion}

Majority of the world is free from polio. Polio still spreads in several countries. In a country which is not free of polio all residents and long-term visitors (i.e. > four weeks) of all ages, should receive a dose of bivalent oral poliovirus vaccine (bOPV) or inactivated poliovirus vaccine (IPV) between four weeks and 12 months prior to international travel. It can helps with restrict of transmission of polio outside the border.

\section{References}

1. Minor P. Poliovirus biology. Structure. 1996;4(7):775-8.

2. Szczepionka przeciw poliomyelitis [Internet]. Szczepienia.Info. [cytowane 25 sierpień 2020]. Dostępne na: https://szczepienia.pzh.gov.pl/szczepionki/poliomyelitis/.

3. Choroba Heinego i Medina - porażenie dziecięce - poliomyelitis - polio. Rozkwit i agonia choroby w dwudziestym wieku - Epidemiological Review (Article in Polish) [Internet]. [downloaded 26 August 2020]. Available at: http://www.przeglepidemiol.pzh.gov.pl/choroba-heinego-i-medina-porazenie-dzieciecepoliomyelitis-polio-rozkwit-i-agonia-choroby-w-dwudziestym-wieku?lang=pl.

4. Muñoz Cobos F, Morales Sutil ML, Faz García MC, Ariza González M, Salazar Agulló JA, Burgos Varo ML. Polio and post-polio syndrome, viewed by patients and health professionals in primary car]. Rev Esp Salud Publica. 2018;92.

5. Lehrer S, Rheinstein PH. Inverse Relationship Between Polio Incidence in the US and Colorectal Cancer. In Vivo. 2018;32(6):1485-9.

6. Macklin G, Diop OM, Humayun A, Shahmahmoodi S, El-Sayed ZA, Triki H, et al. Update on Immunodeficiency-Associated Vaccine-Derived Polioviruses — Worldwide, 2018-2019. MMWR Morb Mortal Wkly Rep. 2020;69(28):913-7.

7. Anand A, Molodecky NA, Pallansch MA, Sutter RW. Immunogenicity to poliovirus type 2 following two doses of fractional intradermal inactivated poliovirus vaccine: A novel dose sparing immunization schedule. Vaccine. 2017;35(22):2993-8.

8. Hampton LM, Farrell M, Ramirez-Gonzalez A, Menning L, Shendale S, Lewis I, et al. Cessation of Trivalent Oral Poliovirus Vaccine and Introduction of Inactivated Poliovirus Vaccine — Worldwide, 2016. Morbidity and Mortality Weekly Report. 2016;65(35):934-8. 
9. Icardi G, Tassinari F. Anti-polio vaccinations in the third millennia. Annali di Igiene Medicina Preventiva e di Comunità. 2018;(4):11-5.

10. Health AGD of Polio anywhere is a risk everywhere [Internet]. Australian Government Department of Health; [downloaded 25 August 2020]. Available at: https://www1.health.gov.au/internet/main/publishing.nsf/Content/cda-cdi3802a.html.

11. Statement of the Eighteenth IHR Emergency Committee Regarding the International Spread of Poliovirus [Internet]. [downloaded 26 August 2020]. Available at: https://www.who.int/news-room/detail/15-08-2018statement-of-the-eighteenth-ihr-emergency-committee-regarding-the-international-spread-of-poliovirus.

12. Statement of the Nineteenth IHR Emergency Committee Regarding the International Spread of Poliovirus [Internet]. [downloaded 26 August 2020]. Available at: https://www.who.int/news-room/detail/30-11-2018statement-of-the-nineteenth-ihr-emergency-committee-regarding-the-international-spread-of-poliovirus.

13. Statement of the Twentieth IHR Emergency Committee [Internet]. [downloaded 26 August 2020]. Available at: https://www.who.int/news-room/detail/01-03-2019-statement-of-the-twentieth-ihr-emergency-committee.

14. Statement of the Twenty-first IHR Emergency Committee Regarding the International Spread of Poliovirus [Internet]. [downloaded 26 August 2020]. Available at: https://www.who.int/news-room/detail/29-05-2019statement-of-the-twenty-first-ihr-emergency-committee.

15. Statement of the Twenty-Second IHR Emergency Committee Regarding the International Spread of Poliovirus [Internet]. [downloaded 26 August 2020]. Available at: https://www.who.int/news-room/detail/03-102019-statement-of-the-twenty-second-ihr-emergency-committee-regarding-the-international-spread-ofpoliovirus.

16. Statement of the Twenty-Third IHR Emergency Committee Regarding the International Spread of Poliovirus [Internet]. [downloaded 26 August 2020]. Available at: https://www.who.int/news-room/detail/07-012020-statement-o-the-twenty-third-ihr-emergency-committee-regarding-the-international-spread-of-poliovirus.

17. Statement of the Twenty-Fourth IHR Emergency Committee [Internet]. [downloaded 26 August 2020]. Available at: https://www.who.int/news-room/detail/08-04-2020-statement-of-the-twenty-fourth-ihr-emergencycommittee.

18. Statement of the twenty-fifth polio IHR Emergency Committee [Internet]. [downloaded 26 August 2020]. Available at: https://www.who.int/news-room/detail/23-06-2020-statement-of-the-25th-polio-ihr-emergencycommittee.

19. Poland GA, Jacobson RM. Understanding those who do not understand: a brief review of the anti-vaccine movement. Vaccine. 2001;19(17):2440-5.

20. The anti-vax movement has been listed by WHO as one of its top 10 health threats for 2019 [Internet]. Newsweek. 2019 [downloaded 26 August 2020]. Available at: https://www.newsweek.com/world-healthorganization-who-un-global-health-air-pollution-anti-vaxxers-1292493.

21. Olive JK, Hotez PJ, Damania A, Nolan MS. The state of the antivaccine movement in the United States: A focused examination of nonmedical exemptions in states and counties. PLOS Medicine. 2018;15(6):e1002578.

22. Skinner E. Vaccination Policies: Requirements and Exemptions for Entering School. 2. 